\title{
DESIGN OF OFDM-BASED RADIO COMMUNICATION SYSTEMS FOR COAST-TO-SEA AND COAST-TO-AIR PROPAGATION ENVIRONMENTS
}

\author{
Sławomir Gajewski, Ph. D. \\ Gdańsk Univeristy of Technology, Poland
}

\begin{abstract}
In the paper the study of radio communication system design process for systems based on OFDM transmission is considered. The signal propagation model for $1.4 \mathrm{GHz}$ frequency band is discussed, and the study of signal propagation characteristics, important from the point of view of OFDM system design, is presented. The methodology of OFDM interface design is proposed and some characteristics of the OFDM-based radio communication system are analysed.
\end{abstract}

Keywords: marine radio communication; wave propagation at sea; ground-to-sea communication; ground-to-air communication; OFDM system design; safety at sea.

\section{INTRODUCTION}

Nowadays the problem of radio communication systems design for maritime applications is very important. It is necessary for the implemented modern wideband systems to enable high-rate data transmission in internet communication and multimedia services. It is commonly agreed that the most interesting signal transmission technique for high-rate data transmission is the OFDM technique, used in the most modern cellular system, called LTE.

This study presents the principle of the use of OFDM technique for design of a wideband radio communication system for maritime applications, especially for A1 sea area, and discusses benefits from its use.

From the point of view of this study some assumptions have been made. First, the frequency band of signals transmitted over the radio communication channel is set equal to $10 \mathrm{MHz}$, which corresponds to one of the most frequently used bands in the LTE public cellular system. This assumption makes it possible to compare the presently obtained results to those achieved for the LTE system.

The centre frequency of the proposed system is set to $1.4 \mathrm{GHz}$. The use of wideband channel means that the signal transmission is done in a frequency-selective multipath channel, which affects the transmission conditions and signal performance. A characteristic transmission feature is that the connection is realized between 2 antennas. The first antenna is localised on the coast, approximately $15 \mathrm{~m}$ above the ground, while the second antenna is localised on a ship in the case of the coast-to-sea channel, or on a plane or helicopter (the coastto-air channel, above the sea). In both cases the same 2-ray propagation model is used [1]. A possible high speed of the plane determines great values of Doppler spread and this is the main difference between these two propagation environments.
The proposed design methodology can be used for adapting modern high-speed data communication systems to maritime applications.

\section{RADIO WAVE PROPAGATION}

The 2-ray propagation model is one of the most often used models for radio-wave propagation in both the coast-to-sea and coast-toair propagation environment. Also propagation measurements in these environments give, in general, similar results.

Using this model we take into account 2 components of the multipath signal propagation. The 1-st is the LOS (lineof-sight) component and the 2-nd is the component reflected from the surface of the sea [1-7].

The model is considered in 2 versions depending on the designed radio station range. The first version is applied when the curvature of the Earth is to be taken into account, and the second - when the surface is assumed flat.

The impulse response of this channel model is given by

$$
h(t, \tau)=\alpha_{0}(t) \delta\left(\tau-\tau_{0}\right)+\alpha_{s}(t) e^{-j 2 \pi \frac{\Delta R_{k}}{\lambda}} \Gamma(t) \delta\left(\tau-\tau_{0}\right)
$$

when:

$\alpha_{0}(t)$ - complex component representing the amplitude of the LOS component,

$\alpha_{s}(t)$-complex component representing the reflected component amplitude,

$\Gamma(t)=\frac{\sin \theta-X}{\sin \theta+X}-$ reflection coefficient from the sea surface,

$e^{-j 2 \pi \frac{\Delta R_{k}}{i}}-$ variable representing the phase shift between the LOS component and the reflected component, depending on the shift $\Delta \mathrm{R}_{\mathrm{k}}=\mathrm{X}+\mathrm{X}^{\prime}-1$ relative to the wavelength $\lambda$. 
The 2-ray model is presented in Fig. 1, where we can find interpretations of formulas for $\Gamma(\mathrm{t})$ and $\Delta \mathrm{R}_{\mathrm{k}}$ (see the model for flat Earth).

In the case of coastal transmission it is possible to receive some additional components reflected from coast obstacles. But the results presented in [1-7] show that they are not important from the point of view of OFDM system design presented in this paper.

\section{PATHLOSS MODELS FOR 1 GHZ (L-BAND) AND 5 GHZ (C-BAND)}

It is very difficult to find publications discussing the issue of loss modelling in systems similar to that analysed in the paper. We can find suitable models in [4-6]. The most recent research which best corresponds to the analysed model of the system was done by NASA [8-9].

The present research concerns the communication between the coast radio station and unmanned aerial vehicles. This research area is very popular nowadays. The research was done on the basis of 2-ray curved-Earth channel model (CE2R). In this model we take into account radio wave reflections from the waving surface of the sea (salty water).

The radio wave reflection from the irregular sea surface may be a reason why waves reach the receiver with large phase-shifts. Thus, it is assumed that the radio wave reaches the receiver as a direct component (LOS) and components reflected from the surface of the water.

The studies take into account the measurements of the radio wave attenuation with deviation dependent on many factors, in particular: water undulation, non-ideal characteristics of the antennas, occasional recording of additional multipath signal components in the receiver (in addition to those corresponding to LOS and the reflected wave), and slow signal strength fluctuations caused by imperfections of the measuring instruments.

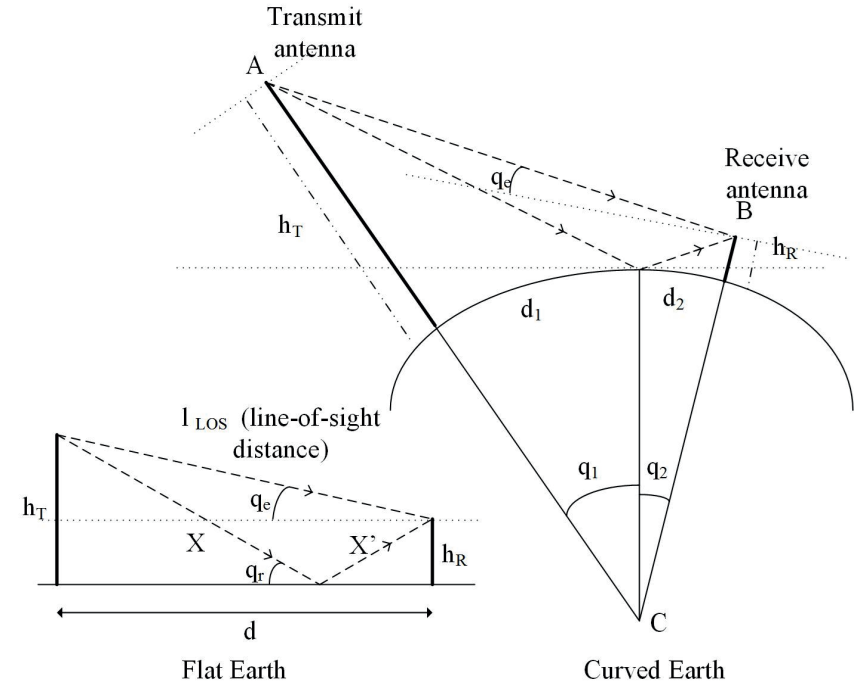

Fig. 1. 2-ray propagation model for flat and curved Earth
As a result, the here proposed propagation models (under the sea surface) are given by formulas (2-4), with parameters shown in Table 1 and Table 2 [8].

For $1 \mathrm{GHz}$ band we have:

$$
L(d, \theta)= \begin{cases}A_{0, l, s}+10 n_{L, s} \log (d)+X_{L, s}+\zeta L_{L, s} & \theta \geq \theta_{t}\left(d \geq d_{t}\right) \\ L_{C E 2 R}+L_{0}+X_{L, l}+\zeta L_{L, l} & \theta<\theta_{t}\left(d<d_{t}\right)\end{cases}
$$

where

$$
L_{C E 2 R}=20 \log \left(\frac{4 \pi d}{\lambda}\right)-20 \log \left(\left|1+D \Gamma_{p} e^{-j \frac{2 \pi \Delta R}{\lambda}}\right|\right)
$$

And for $5 \mathrm{GHz}$ band we have:

$$
L(d, \theta)= \begin{cases}A_{0, C, s}+10 n_{C, s} \log (d)+X_{C, s}+\zeta L_{C, s} & \theta \geq \theta_{t}\left(d \geq d_{t}\right) \\ A_{0, l}+10 n_{C, l} \log (d)+X_{C, l}+\zeta L_{C, l} & \theta<\theta_{t}\left(d<d_{t}\right)\end{cases}
$$

The used parameters are as follows:

$\mathrm{A}_{0, \mathrm{~L}, \mathrm{~s}}$ - propagation constant for $1 \mathrm{GHz}$ band,

$\mathrm{nL}, \mathrm{s}$ - power of signal loss for $1 \mathrm{GHz}$ band,

$\mathrm{LL}, \mathrm{s}$ - correction factor for $1 \mathrm{GHz}$ frequency band,

d - distance between antennas,

$\mathrm{X}_{\mathrm{L}, \mathrm{s}} \mathrm{X}_{\mathrm{L}, \mathrm{l}}-$ Gaussian variables of zero mean value and standard deviations $\sigma_{\mathrm{X}, \mathrm{L}, \mathrm{S}}[\mathrm{dB}]$ and $\boldsymbol{\sigma}_{\mathrm{X}, \mathrm{L}, \mathrm{l}}[\mathrm{dB}]$, respectively,

$\zeta$ - constant depending on the direction of vehicle motion: from the coast station to the vehicle $\zeta=1$ or to the coast station $\zeta=-1$,

$\mathrm{L}_{\mathrm{CE} 2 \mathrm{R}}$ - signal loss for the CE2R model and the instantaneous current location of antennas.

$\mathrm{L}_{0}$ - correction factor for the CE2R model,

$\mathrm{L}_{\mathrm{L}, 1}$ - correction factor for $1 \mathrm{GHz}$,

$\lambda$ - wave length,

D - divergence factor due to spherical Earth shape,

$\Gamma_{\mathrm{p}}$ - surface reflection coefficient, with the subscript $\mathrm{p}$ denoting the impinging wave polarization,

$\Delta \mathrm{R}$ - relative path length difference between LOS and surface reflection,

$\sigma_{\mathrm{X}, \mathrm{L}, \mathrm{s}}-$ standard deviation of the $\mathrm{X}_{\mathrm{L}, \mathrm{s}}$ random variable representing signal fluctuations,

$\sigma_{\mathrm{X}, \mathrm{L}, \mathrm{l}}$ - standard deviation of the $\mathrm{X}_{\mathrm{L}, \mathrm{l}}$ random variable representing slow signal fluctuations,

$\mathrm{A}_{0, \mathrm{C}, \mathrm{s}}$ - propagation constant for $5 \mathrm{GHz}$ band,

$\mathrm{n}_{\mathrm{Cs}}$ - power of signal loss for $5 \mathrm{GHz}$,

$\mathrm{X}_{\mathrm{C}, \mathrm{s}} \mathrm{X}_{\mathrm{C}, \mathrm{l}}-$ Gaussian variables of zero mean value and standard deviations $\sigma_{\mathrm{X}, \mathrm{C}, \mathrm{s}}[\mathrm{dB}]$ and $\sigma_{\mathrm{X}, \mathrm{C}, 1}[\mathrm{~dB}]$, respectively,

$\mathrm{L}_{\mathrm{C}, \mathrm{s}}$ - correction factor for $5 \mathrm{GHz}$,

$\sigma_{\mathrm{XC}, \mathrm{s}}$ - standard deviation of $\mathrm{X}_{\mathrm{C}, \mathrm{s}}$ random variable representing slow signal fluctuations,

$\sigma_{\mathrm{XC}, 1}-$ standard deviation of $\mathrm{X}_{\mathrm{C}, 1}$ random variable representing slow signal fluctuations,

$\mathrm{A}_{0,1}$ - propagation constant for $5 \mathrm{GHz}$,

$\mathrm{n}_{\mathrm{C}, 1}-$ power of signal loss for $5 \mathrm{GHz}$,

$\mathrm{L}_{\mathrm{C}, 1}$ - correction factor for $5 \mathrm{GHz}$,

$\mathrm{d}_{\mathrm{t}}-$ distance $2.2 \leq \mathrm{d} \leq 24 \mathrm{~km}$ for the sea water, 
The proposed values for the used parameters are collated in Table 1 and Table 2, for $1 \mathrm{GHz}$ and $5 \mathrm{GHz}$ frequency, respectively.

Selection of the model depends on the adopted threshold of elevation angle $\theta_{t}$ - which represents the angle between the tangent to the Earth surface at the point where the coast radio station antenna is situated, and the line from that point to the antenna on the vehicle (the plane or the ship).

It also depends on the distance $d_{t}$ between the positions of the coast station antenna and the vehicle antenna (the latter being defined as the point on the ground designated by the perpendicular to the tangent to the ground at that point and the proposed vehicle antenna height).

In general, values achieved for a small elevation angle can be understood as referring to:

- the ship, for the coast-to-sea model

- the climb phase of the aircraft, for the coast-to-air model,

- or the flight at a relatively low altitude, for the coastto-air model.

Tab. 1. Path loss parameters for $1 \mathrm{GHz}$ [8]

\begin{tabular}{|c|c|}
\hline Parameter & Value \\
\hline$A_{0, L, s}[\mathrm{~dB}]$ & 50.6 \\
\hline$n_{L, s}$ & 1.5 \\
\hline$\sigma_{X, L, s}[\mathrm{~dB}]$ & 2.8 \\
\hline$L_{L, s}[\mathrm{~dB}]$ & 1.2 \\
\hline$L_{0}[\mathrm{~dB}]$ & 1.0 \\
\hline$\sigma_{X, L, l}[\mathrm{~dB}]$ & 4.8 \\
\hline$L_{L, l}[\mathrm{~dB}]$ & 1.1 \\
\hline $\mathrm{d}_{\mathrm{t}}[\mathrm{km}]$ & 9.1 \\
\hline
\end{tabular}

Tab. 2. Path loss parameters for $1 \mathrm{GHz}$ [8]

\begin{tabular}{|c|c|}
\hline Parameter & Value \\
\hline$A_{0, C, s}[\mathrm{~dB}]$ & 60 \\
\hline$n_{C, s}$ & 1.6 \\
\hline$\sigma_{X, C, s}[\mathrm{~dB}]$ & 2.3 \\
\hline$L_{C, s}[\mathrm{~dB}]$ & 1.7 \\
\hline$A_{0, l}[\mathrm{~dB}]$ & 63,9 \\
\hline$n_{C, l}$ & 1.5 \\
\hline$\sigma_{X, C, l}[\mathrm{~dB}]$ & 2.5 \\
\hline$L_{C, l}[\mathrm{~dB}]$ & 0.5 \\
\hline $\mathrm{d}_{\mathrm{t}}[\mathrm{km}]$ & 9.1 \\
\hline
\end{tabular}

It is noteworthy that under the tested conditions, the correlation time and the delay spread were very small. In a typical situation the delay spread was less than $50 \mathrm{~ns}$, and only occasionally increased to $250 \mathrm{~ns}$. But we should keep in mind that the developed model has also to take into account situations when the delay spread is larger due to larger channel selectivity.

Based on the conclusion resulting from observations of the models, authors propose to modify slightly the basic CE2R model (by adding two more components) for signal loss estimation at low altitude and frequencies close to $1 \mathrm{GHz}$ what we can see in the formula (2). At the same time for higher altitudes $\left(\theta>\theta_{t}\right)$ the modified model is taken into account (see (2)). This model is only loosely associated with the CE2R model.Consequently, the CE2R model is valid for ships and low-altitude flights and climbing.

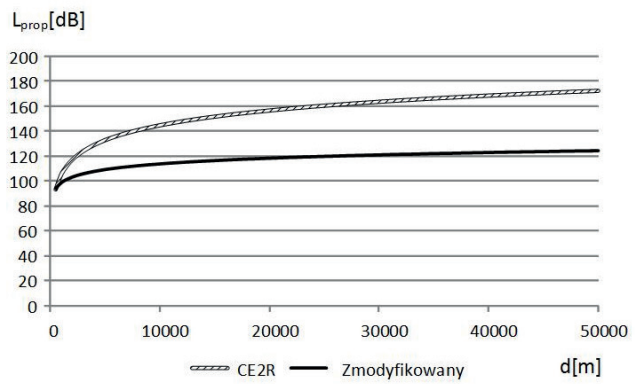

Fig. 2. Charts of propagation loss using the models given by (2) and (3) (excluding the random variable $X ; \zeta=1$ )

Signal losses $\mathrm{L}_{\text {prop }}$ obtained using these two models are compared in Fig. 2, presenting this quantity as a function of the distance between antennas. As we can see, the CE2R model is more restrictive than the modified one. Taking into account the empirical nature of the research, the modified model seems to be more appropriate. Consequently, the authors decided to forsake the CE2R model for the $5 \mathrm{GHz}$ band for both low and high altitudes (see the formula (4)).

It is noteworthy that for maritime conditions of signal propagation the path loss is usually larger than in the case of coast-to-air transmission.

\section{PROPAGATION LOSS MODEL PROPOSAL FOR 1.4 GHZ}

For $1.4 \mathrm{GHz}$ transmission, the model for $1 \mathrm{GHz}$ seems to be more adequate, and this model was used in the analysis. The frequency increase to $1.4 \mathrm{GHz}$ results in larger signal loss, as we can see in Table 3. But the assumed parameters need verification in relevant measurements, which is planned in the future.

In the first approach we can assume that the signal loss along the Earth surface is given by

$$
L[d B]=\left\{\begin{array}{lr}
A_{0, l}+10 n_{l} \log (d)+X_{l}+\zeta L_{l} & \theta \geq \theta_{t} \text { for planes } \\
A_{0, s}+10 n_{s} \log (d)+X_{s}+\zeta L_{s} & \theta<\theta_{t} \text { for planes } \\
A_{0, s 2}+10 n_{s 2} \log (d)+X_{s 2}+\zeta L_{s 2} & \theta<\theta_{t} \text { for ships }
\end{array}\right.
$$

with parameter values given in Tab. 3 .

Tab. 3. Proposed path loss parameters for $1.4 \mathrm{GHz}$ [8]

\begin{tabular}{|c|c|}
\hline Parameter & Value \\
\hline$A_{0, l}[\mathrm{~dB}]$ & 52,6 \\
\hline$n_{l}$ & 1.5 \\
\hline$\sigma_{X l}[\mathrm{~dB}]$ & 2.7 \\
\hline$L_{l}[\mathrm{~dB}]$ & 1.3 \\
\hline$A_{0, s}[\mathrm{~dB}]$ & 55,3 \\
\hline$n_{s}$ & 1.5 \\
\hline$\sigma_{X s}[\mathrm{~dB}]$ & 4.8 \\
\hline$L_{s}[\mathrm{~dB}]$ & 1.1 \\
\hline$d_{t}[\mathrm{~km}]$ & 9.1 \\
\hline$A_{0, s 2}[\mathrm{~dB}]$ & 60,3 \\
\hline$n_{s}$ & 2.6 \\
\hline$\sigma_{X s}[\mathrm{~dB}]$ & 4.8 \\
\hline$L_{s}[\mathrm{~dB}]$ & 1.1 \\
\hline
\end{tabular}


The parameters used in (5) are then as follows:

$\mathrm{A}_{0,1}$ - propagation constant for high flight altitude phase (coast-to-air model),

$\mathrm{n}_{0,1}$ - signal loss power for high flight altitude,

$\sigma_{\mathrm{xl}}$ - standard deviation of random variable $\mathrm{X}_{1}$ representing slow signal fluctuations,

$\mathrm{L}_{1}$ - correction factor for high flight altitude,

$\mathrm{A}_{0, \mathrm{~s}}$ - propagation constant for low flight altitude phase (coast-to-air model),

$\mathrm{n}_{0, \mathrm{~s}}$ - signal loss power for low flight altitude,

$\sigma_{\mathrm{Xs}}-$ standard deviation of random variable $\mathrm{X}_{\mathrm{s}}$ representing slow signal fluctuations,

$\mathrm{L}_{\mathrm{s}}$ - correction factor for low flight altitude,

$\mathrm{A}_{0, \mathrm{~s} 2}$-propagation constant for ships (coast-to-sea model),

$\mathrm{n}_{0, \mathrm{~s} 2}-$ signal loss power for ships,

$\sigma_{\mathrm{Xs} 2}$ - standard deviation of random variable $\mathrm{X}_{\mathrm{s} 2}$ representing slow signal fluctuations,

$\mathrm{L}_{\mathrm{s} 2}-$ correction factor for ships,

$\mathrm{d}$ - distance between antennas,

$\mathrm{X}_{1}, \mathrm{X}_{\mathrm{s}}, \mathrm{X}_{\mathrm{s} 2}-$ Gaussian variables of zero mean value and standard deviations $\sigma_{\mathrm{Xl}}[\mathrm{dB}], \sigma_{\mathrm{Xs}}[\mathrm{dB}], \sigma_{\mathrm{Xs} 2}[\mathrm{~dB}]$, respectively

$\zeta$ - constant depending on motion direction from the coast station $\zeta=1$ (moving out) or to the coast station $\zeta=-1$ (moving to the coast).

\section{$L_{\text {prop }}[\mathrm{dB}]$}

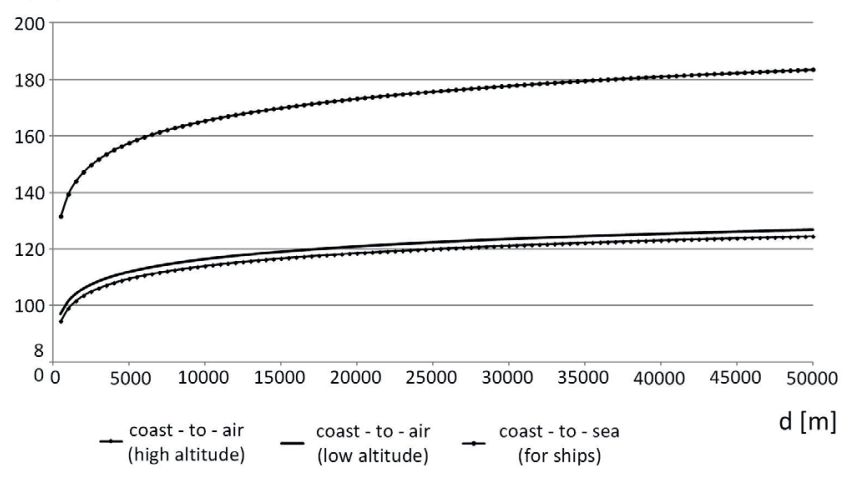

Fig. 3. Signal loss as a function of the distance, using (4) (excluding the random variable $X ; \zeta=1$ )

Charts of signal loss for the proposed model are presented in Fig. 3. We can see that the model for coast-to-sea transmission is more restrictive than the models for coastto-air transmission.

\section{GENERAL MODEL OF WIDEBAND CHANNEL}

The model of wideband channel can be presented as the FIR filter, consisting of the delay line and not more than 4 branches, see Fig. 4 . The received signal $y(t)$ is the vector sum of signals received in different propagation paths with various delays and phases. The first component is the LOS signal, of instantaneous complex amplitude $\alpha_{0}(t)$ and phase shift $\phi_{0}$. The amplitude probability of this component is given by the Rician distribution. The 2-nd component, of the $\alpha_{s}(t)$ amplitude and $\phi$ s phase shift, is the result of reflection from the sea surface.

The remaining components $z_{1}(t)$ and $z_{2}(t)$ additionally depend on stochastic processes which determine their existence.

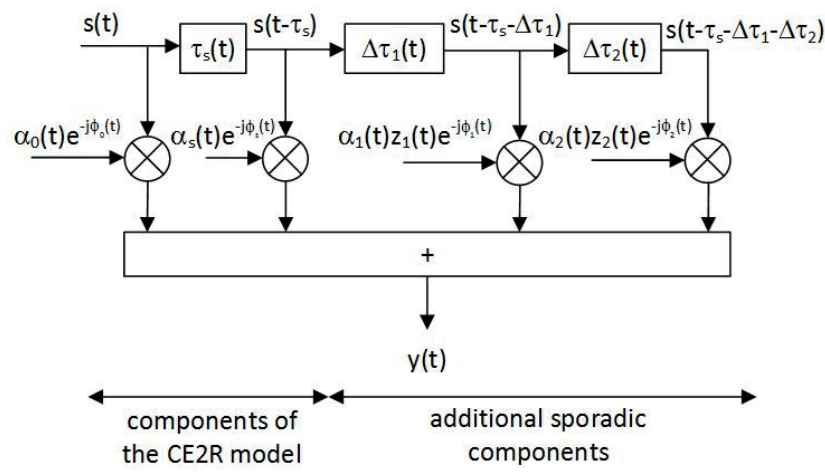

Fig. 4. Model of wideband channel

The probability distribution of the occurrence of these components is largely undefined. Nevertheless, the probability of the amplitude component of the second and other components is believed to results from the Rayleigh distribution.

\section{MAIN PARAMETERS OF THE CHANNEL}

\section{CORRELATION TIME AND DELAY SPREAD}

The research presented in [8-12] suggests that the correlation time and the delay spread for the here analysed propagation environments are very short. The delay spread was measured for a short distance between the vehicle and the coast station, and for a larger distance. In general, the delay spread is very short for the larger distance, and slightly longer for the short distance. But in both cases it does not, generally, exceed $50 \mathrm{~ns}$, and only in most critical situations increases to $250 \mathrm{~ns}$. This is very important information from the point of view of the OFDM system design, because small delay spread means that small time guard $\mathrm{T}_{\mathrm{g}}$ between OFDM symbols is required. From the literature $[11,13]$ we know that the time guard should be a few times larger than the maximum delay spread, in order to take into account the most critical situations occurring in the propagation environment.

It appears from the presented considerations that we can set the minimum time guard approximately equal to $1 \mu \mathrm{s}$. As a comparison, it is approximately 5 times shorter than the so-called short time guard used in LTE. That means that the OFDM technique is more suitable for the use in sea propagation environment than LTE, as compared to urban, suburban or rural environments.

As a result of the above reasoning, the value of minimum acceptable time guard was set to

$$
T_{g, \min }=1 \mu s
$$




\section{COHERENCE BANDWIDTH AND ADAPTIVE CORRECTION OF SIGNALS IN THE RECEIVER}

The coherence bandwidth $\mathrm{B}_{\mathrm{c}}$ of the multipath channel in which the correlation time equals several dozen ns can be, approximately, slightly larger than a dozen $\mathrm{MHz}$, and for a few hundred ns - approximately equal to a few $\mathrm{MHz}$. That means that within the band of the received signal $(\mathrm{B}=10$ $\mathrm{MHz}$ ), no more than one minimum (strongly suppressed component-subcarrier of the spectrum) should be observed. And in the general case, no strongly suppressed component may be observed. However, a longer correlation time, reaching a few $\mu$ s, can cause a strong frequency selectivity.

It means that in relatively long periods of time the channel cannot be frequency selective, despite a large channel bandwidth. In this case we do not need to use correction of channel pulse response in the receiver, nor other simple solutions.

\section{GENERAL METHODOLOGY OF OFDM INTERFACE DESIGN}

As the first step, we assume the FFT size which depends on the planned number of subcarriers in the OFDM signal. Most frequently the FFT size is assumed as the power of 2 . The 1024 size is preferred for a few hundred of active subcarriers, which is the case of the present project. If the designed number of subcarriers is smaller than the FFT size, then we only use active subcarriers and set other subcarriers equal to zero.

Subcarrier spacing should be much larger than the Doppler spread, which in the designed system depends on the speed of motion of vehicles. Therefore in order to take into account high speed of motion of terminals, higher $\Delta \mathrm{f}$ should be assumed. In a typical situation, the $\Delta \mathrm{f}$ value of over dozen $\mathrm{kHz}$ is sufficient even for very large (more than $1000 \mathrm{kmph}$ ) vehicle speed.

The subcarrier spacing must meet the condition

$$
\Delta f>\Delta f_{\text {doopler }}
$$

The sampling frequency depends on the assumed $\Delta \mathrm{f}$ and the number of subcarriers $\left(\mathrm{FFT}_{\text {size }}\right)$. This relation is

$$
f_{s}=F F T_{S I Z E} \cdot \Delta f
$$

The OFDM symbol duration depends on the assumed value of $\Delta \mathrm{f}$

$$
T_{\text {OFDM }}=\frac{1}{\Delta f}
$$

In the next step, the total symbol transmission period $\mathrm{T}_{\mathrm{TR}}$ is to be estimated. It depends on the number of designed OFDM symbols per time unit and the duration of a single time slot. In the proposed system the time slot duration is equal to $\mathrm{T}_{\text {slot }}=0.5 \mathrm{~ms}$, and a single slot can transmit $\left(\mathrm{N}_{\text {symb }}\right) 6$, 7 or 8 OFDM symbols. Then the total transmission period is

$$
T_{T R}=\frac{T_{\text {slot }}}{N_{\text {symb }}}
$$

Hence we have

$$
T_{T R}=T_{O F D M}+T_{g}
$$

If we know the $\mathrm{T}_{\text {OFDM }}$ symbol duration then we can estimate the possible time guard $\mathrm{T}_{\mathrm{g}}$ between the transmitted OFDM symbols.

The most critical assumption for OFDM-based systems is that the $\mathrm{T}_{\mathrm{g}}$ should be shorter than the maximum delay spread in the designed system. It means that

$$
T_{g}<\Delta T_{\text {delay }}
$$

and preferably $\mathrm{T}_{\mathrm{g}}<<\Delta \mathrm{T}_{\text {delay }}$.

Here we assumed that $\mathrm{T}_{\mathrm{g}}$ should be a few times shorter than $\Delta \mathrm{T}_{\text {delay }}$, as a minimum, in a large percent of time.

\section{CHARACTERISTICS OF PROPOSED OFDM SYSTEM}

The transmission of signals in the proposed system is realized in TDD mode in a single frequency channel of 10 $\mathrm{MHz}$ frequency band. The working frequency is $1.4 \mathrm{GHz}$.

Tab. 4. Basic parameters for proposed radio interface

\begin{tabular}{|l|l|}
\hline Parameter & Value \\
\hline Multiple access & OFDMA \\
\hline Duplex method & TDD \\
\hline $\begin{array}{l}\text { Channel centre } \\
\text { frequency }\end{array}$ & $1.4 \mathrm{GHz}$ \\
\hline Channel band & $10 \mathrm{MHz}$ \\
\hline Modulation & QPSK and 16 QAM \\
\hline Channel coding & Convolutional coding $(3,1,9)$ \\
\hline FFT size & 1024 \\
\hline $\begin{array}{l}\text { Number of OFDM } \\
\text { symbols in a single slot } \\
\text { (per 0.5 ms) }\end{array}$ & 6,7 or 8 \\
\hline Physical resource size & $\begin{array}{l}12 \text { subcarriers x } 8 \text { (7 or 6) } \\
\text { OFDM symbols }\end{array}$ \\
\hline
\end{tabular}

In the radio interface we use the OFDM technique, in which the transmission over the entire frequency band is done using a number of orthogonal subcarriers transmitted simultaneously. This transmission method increases the immunity of the transmitted signal to frequency selective signal fading, which is the most problematic issue in wideband radio communication systems. The basic set of parameters is given in Table 4 .

\section{THE STRUCTURE OF PHYSICAL RESOURCE BLOCK}

The basic unit of resources is the resource block. The resource block size in the system is defined in the timefrequency domain. In the time domain, the resources are divided depending on the number of OFDM symbols used in a single time slot, while in the frequency domain they are divided into a number of subcarriers. The size of the designed block is 12 subcarriers and 6, 7 or 8 OFDM symbols in a single slot, see Fig. 5 . 


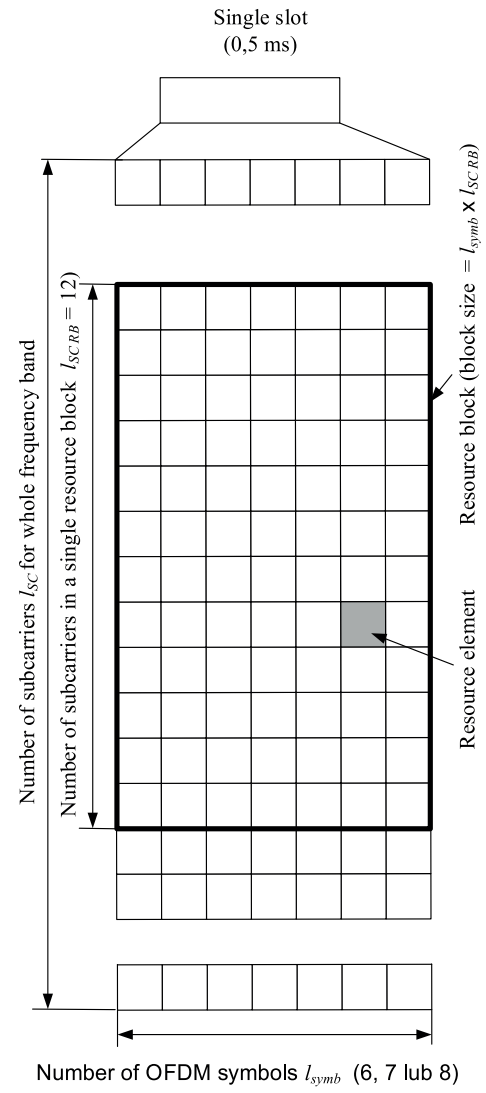

Fig. 5. The structure of physical resource block

The number of resource blocks depends on the set subcarrier spacing, which is the main issue of the analysis. A single resource block consists of data sent on 12 subcarriers in a single slot of $0.5 \mathrm{~ms}$ duration. The block size depends on the number of OFDM symbols per slot. A single resource element carries 2 or 4 bits, depending on the modulation type: QPSK or 16 QAM, respectively. So, the resource element it is the smallest unit of information sent on a single subcarrier in time duration of a single OFDM symbol.

\section{ANALYSIS RESULTS}

Table 5 collates results of calculation of OFDM system parameters for different values of OFDM symbols and subcarrier spacing. It determines the guard time $\mathrm{T}_{\mathrm{g}}$ for different configurations, some of which can be accepted for the system or not.

For comparison purposes, the table includes parameters calculated for the LTE system. The $\mathrm{R}_{\mathrm{p}} / \mathrm{R}_{\min }$ value is the indicator for the use of resources, calculated as the available throughput normalized by the minimum throughput available for the analysed conditions (in the present case it corresponds to the value for LTE with 6 OFDM symbols per slot). As we can see, the best proposal is for 8 OFDM symbols per slot when the calculated guard time is $\mathrm{T}_{\mathrm{g}}=1.26 \mu \mathrm{s}$, assuming that $\mathrm{T}_{\mathrm{g}}$ should be greater than $1 \mu \mathrm{s}$. Additionally, Fig. 6 shows the results of $\mathrm{T}_{\mathrm{g}}$ calculation as a function of $\Delta \mathrm{f}$, for different number of OFDM symbols, to illustrate the effect of subcarrier spacing on the guard time acceptable in the system.
The first conclusion after analysing these results is that larger number of OFDM symbols not always results in greater throughput. But large number of OFDM symbols is preferred, as it is achieved when $\Delta \mathrm{f}$ is larger. And larger values of $\Delta \mathrm{f}$ are preferable for high speeds of vehicles (which is not important for ships but very important for planes).

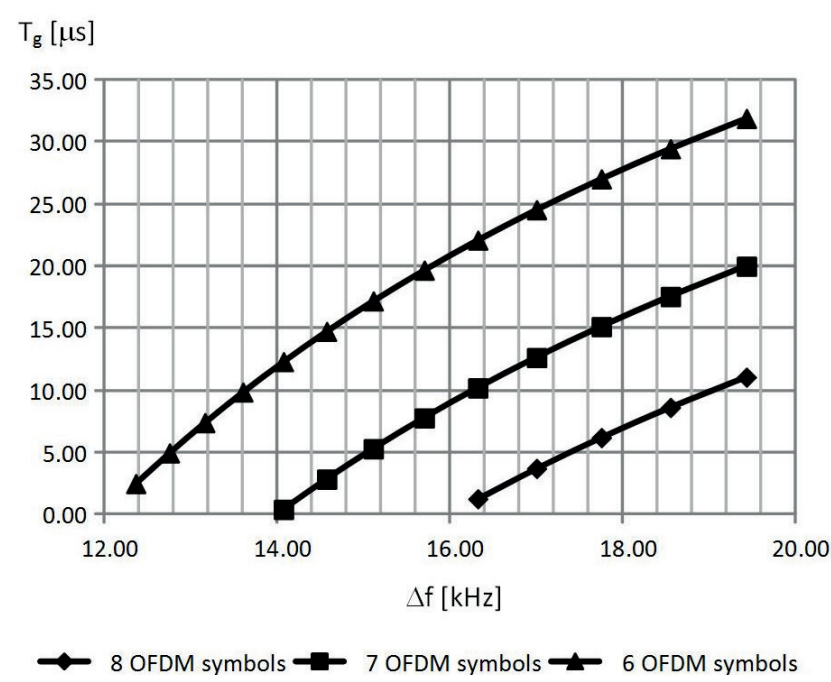

Fig. 6. Time guard as function of subcarrier spacing for different numbers of OFDM symbols in single slot

The second conclusion is that the coast-to-sea and coastto-air environments are very good from the viewpoint of the use of OFDM transmission for data transmission, because we can use small $\mathrm{Tg}$ periods at relative large $\Delta \mathrm{f}$ values. It is possible to use large number of OFDM symbols for a single slot, which guarantees high spectral efficiency.

Another interesting problem is the normalized throughput available in different configurations of $\Delta \mathrm{f}$ and $\mathrm{T}_{\mathrm{g}}$. Relevant results are presented in Fig. 7.

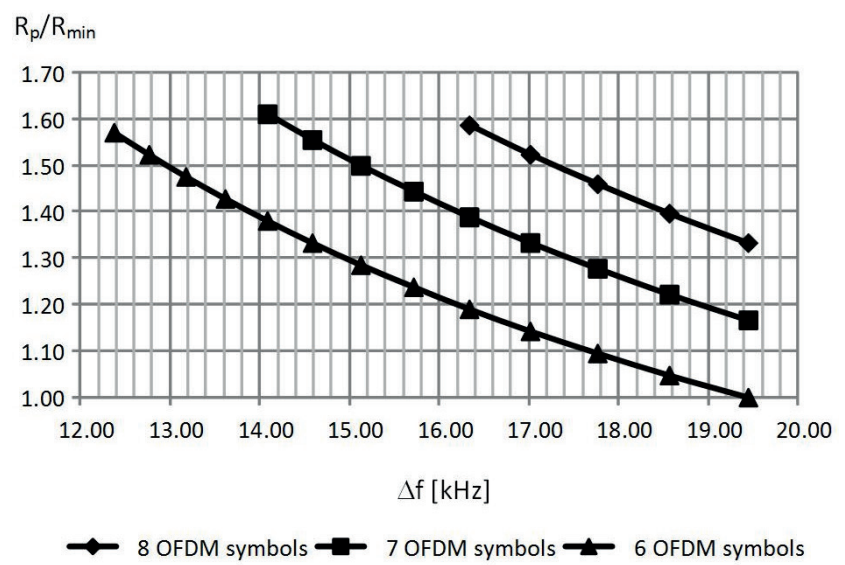

Fig. 7. Normalized throughput as function of subcarrier spacing for different numbers of OFDM symbols in single slot.

If we take into account a smaller number of OFDM symbols in the slot then we can achieve the same throughput using a smaller $\Delta \mathrm{f}$ value, as compared to the case of greater number of OFDM symbols. But if a larger $\Delta \mathrm{f}$ is preferred, it is more appropriate to use a greater number of OFDM symbols. 
Tab. 5. Results of estimation of OFDM parameters for different operating conditions

\begin{tabular}{|c|c|c|c|c|c|c|c|c|c|c|c|c|}
\hline & & & & \multicolumn{3}{|c|}{6 symbols } & \multicolumn{3}{|c|}{7 symbols } & \multicolumn{3}{|c|}{8 symbols } \\
\hline & $\mathrm{RB}$ & $\Delta \mathrm{f}$ & $\begin{array}{c}\text { TofDM } \\
{[\mu \mathrm{s}]}\end{array}$ & $\begin{array}{c}\text { TofDM }^{\text {Tor }} \mathrm{T}_{\mathrm{g}} \\
{[\mu \mathrm{s}]}\end{array}$ & $\begin{array}{c}\mathrm{T}_{\mathrm{g}} \\
{[\mu \mathrm{s}]}\end{array}$ & $\mathrm{R}_{\mathrm{p}} / \mathrm{R}_{\min }$ & $\begin{array}{c}\text { TofDM }+T_{g} \\
{[\mu \mathrm{s}]}\end{array}$ & $\begin{array}{c}\mathrm{T}_{\mathrm{g}} \\
{[\mu \mathrm{s}]}\end{array}$ & $\mathrm{R}_{\rho} / \mathrm{R}_{\min }$ & $\begin{array}{c}\mathrm{T}_{\text {OFDDM }}+T_{\mathrm{g}} \\
[\mu]]\end{array}$ & $\begin{array}{c}\mathrm{T}_{\mathrm{g}} \\
{[\mu \mathrm{s}]}\end{array}$ & $\mathrm{R}_{\mathrm{p}} / \mathrm{R}_{\min }$ \\
\hline \multirow{11}{*}{ 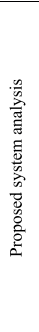 } & 44 & 18,56 & 53,88 & \multirow{11}{*}{83,33} & 29,45 & 1,05 & \multirow{7}{*}{71,43} & 17,55 & 1,22 & \multirow{3}{*}{62,50} & 8,62 & 1,40 \\
\hline & 46 & 17,76 & 56,31 & & 27,03 & 1,10 & & 15,12 & 1,28 & & 6,19 & 1,46 \\
\hline & 50 & 16,33 & 61,24 & & 22,10 & 1,19 & & 10,19 & 1,39 & & 1,26 & 1,59 \\
\hline & 52 & 15,71 & 63,65 & & 19,68 & 1,24 & & 7,77 & 1,44 & \multirow{8}{*}{\multicolumn{3}{|c|}{ non - realizable }} \\
\hline & 54 & 15,12 & 66,14 & & 17,20 & 1,29 & & 5,29 & 1,50 & & & \\
\hline & 56 & 14,58 & 68,59 & & 14,75 & 1,33 & & 2,84 & 1,56 & & & \\
\hline & 58 & 14,08 & 71,02 & & 12,31 & 1,38 & & 0,41 & 1,61 & & & \\
\hline & 60 & 13,61 & 73,48 & & 9,86 & 1,43 & \multirow{4}{*}{\multicolumn{3}{|c|}{ non - realizable }} & & & \\
\hline & 62 & 13,17 & 75,93 & & 7,40 & 1,48 & & & & & & \\
\hline & 64 & 12,76 & 78,37 & & 4,96 & 1,52 & & & & & & \\
\hline & 66 & 12,37 & 80,84 & & 2,49 & 1,57 & & & & & & \\
\hline \multirow[t]{2}{*}{ 㬞 } & & & & \multicolumn{3}{|c|}{$\begin{array}{l}\text { long cyclic prefix } \\
(16,67 \mu \mathrm{s}) 6 \text { symbols }\end{array}$} & \multicolumn{3}{|c|}{$\begin{array}{l}\text { short cyclic prefix } \\
(5,2 \mu \mathrm{s} \text { and } 4,69 \mu \mathrm{s}) 7 \text { symbols }\end{array}$} & \multicolumn{3}{|c|}{8 symbols } \\
\hline & 50 & 15,00 & 66,67 & 83,33 & 16,67 & 1,19 & 71,43 & $\sim 4,76$ & 1,39 & & $\begin{array}{l}\text { non - real } \\
\text { nets }\end{array}$ & \\
\hline
\end{tabular}

Figure 8 illustrates a very interesting case when the normalized throughput is analysed as a function of the guard time. In Fig. 8 a the full range of guard time is presented, while Fig. 8 b shows only, for better visualisation, the magnified range of short guard time.

We can see that the greatest throughput is achieved for the largest number of OFDM symbols in a single slot. For 7 symbols the throughput highest than 1.56 is not realizable due to excessively short guard time in this case (non acceptable $\mathrm{T}_{\mathrm{g}}$ - less than $\left.1 \mu \mathrm{s}\right)$. That is why this throughput is considered worse than that achieved for 6 OFDM symbols.

What is very important is that the optimum number of OFDM symbols is dependent on the designed guard time and its restrictions. Note that the system is realizable only for parameters marked as points in this figure because it is dependent on the predefined resource block size (positions of these points depend on the resource block size).

For instance, from Fig. 8 we can see that:

- for $\mathrm{T}_{\mathrm{g}}=2.5 \mu$ s the best throughput is with 6 OFDM symbols only,

- for $\mathrm{T}_{\mathrm{g}}=2.85 \mu \mathrm{s} 7$ the use of 7 symbols is more favourable

- but for $\mathrm{T}_{\mathrm{g}}=3,71 \mu$ s the best situation is when 8 symbols per slot are implemented.

In Fig. 8a the throughput available in LTE is compared to that of the proposed system, for 2 possible configurations of Tg in LTE (so-called short cyclic prefix and long cyclic prefix). We can see that the band of $9 \mathrm{MHz}$, against $10 \mathrm{MHz}$ available in LTE, at the assumed values of $\mathrm{Tg}$ and $\Delta \mathrm{f}$ result in much poorer efficiency of LTE, as compared to the proposed system.

\section{CONCLUSION}

The paper proposes a design of OFDMA-based system for maritime applications. The performed analyses have revealed that for coast-to-sea and coast-to air (above the sea surface) propagation environments, very short guard periods between the transmitted OFDM symbols can be used, which provides very good conditions for OFDMA interfaces performance and enables to achieve high efficiency of the use of radio resources. These conditions are much better than those characteristic for urban and rural environments. It means that the OFDM technique is strongly recommended for use in maritime radio communication systems.

The proposed method can be adopted in multi-carrier systems (MC-CDMA [14]). Moreover, the proposed solution can be implemented in systems using advanced frequency reuse methods, described in [15-16].

The presented analysis also reveals that the configuration of OFDM parameters for LTE is much more unfavorable, from the viewpoint of resource use, than the configurations of the proposed system.

The proposed path loss model can be taken into account when estimating the coverage of the proposed system working on the $1.4 \mathrm{GHz}$ band.

a)

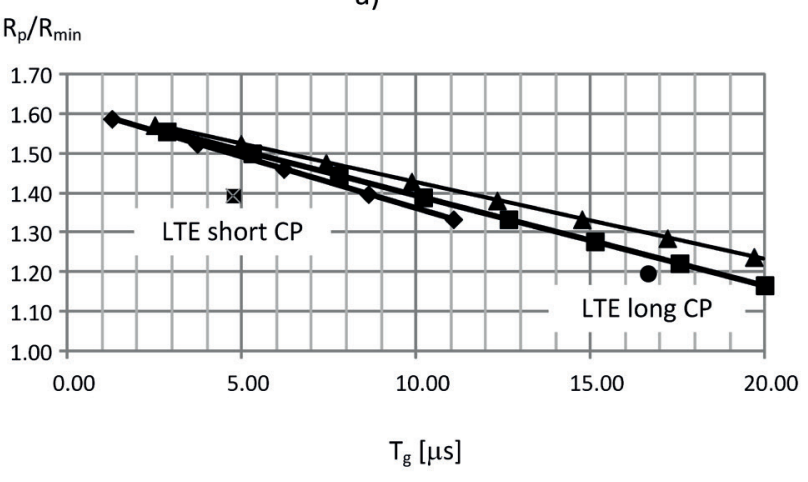

8 OFDM symbols 7 OFDM symbols 6 OFDM symbols

- LTE 6 symbols LTE 7 symbols

$\mathrm{R}_{\mathrm{p}} / \mathrm{R}_{\min }$

b)

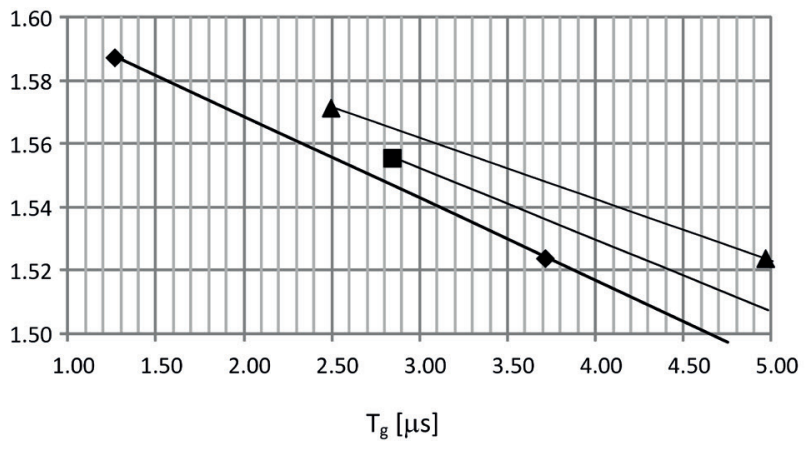

$\rightarrow 8$ OFDM symbols $\rightarrow-7$ OFDM symbols $\rightarrow 6$ OFDM symbols

Fig. 8. Normalized throughput as function of time guard for different numbers of OFDM symbols in single slot:

a) full range of available subcarrier spacing and results for LTE; b) narrowed range for better presentation of the best results. 


\section{ACKNOWLEDGMENTS}

This work was financially supported by Polish National Centre for Research and Development under grant no. DOB-BIO6/09/5/2014.

\section{BIBLIOGRAPHY}

1. Parsons J.D., The mobile radio propagation channel, 2nd ed. Wiley 2000.

2. Zajic A., Mobile-to-Mobile Wireless Channels, Artech House, 2013.

3. Matolak D., AG Channel Sounding for UAS in the NAS, NASA, Project presentation, University of South California, 2014.

4. Matolak D., Sun R., Antenna and Frequency Diversity in the Unmanned Aircraft Systems Bands for the OverSea Setting, Project presentation, University of South California, 2014.

5. Matolak D., Sun R., Air-Ground Channel Characterization for Unmanned Aircraft Systems: The Over-Freshwater Setting, 978-1-4799-4891-8/14/\$31.00 2014 IEEE.

6. Matolak D., Air-Ground Channels\&Models: Comprehensive Review and Considerations for Unmanned Aircraft Systems, 978-1-4577-0557-1/12/\$26.00 2012 IEEE.

7. Venkatasubramanian S. N., Propagation channel model between unmanned aerial vehicles for emergency communications, Thesis submitted for MSc, Alto University 2013.

8. Matolak D., Shalkhauser K., Kerczewski R, L-Band and C-Band Air-Ground Channel Measurement \& Modeling Update, Aeronautical Communications Panel, 31st Meeting of Working Group F, Seattle, Washington, USA, 2014.

9. Matolak D., Shalkhauser K., Kerczewski R, L-Band and C-Band Air-Ground Channel Measurement \& Modeling for Over-Sea Conditions, Aeronautical Communications Panel, 30th Meeting of Working Group F, Seattle, Washington, USA, 2014.

10. Newhall W.G., Mostafa R., Dietrich C., Anderson C. R., Dietze K., Joshi G., Reed J.H., Wideband Air-to-Ground Radio Channel Measurements Using Antenna Array at $2 \mathrm{GHz}$ for Low-Altitude Operations, 0-7803-81408/03/\$17.00 2003 IEEE.

11. Haque J., An OFDM Based Aeronautical Communication System, PhD dissertation, University of South Florida, 2011.
12. Lee Y.H., Dong F., Meng Y.S., Near Sea-Surface Mobile Radiowave Propagation at $5 \mathrm{GHz}$ : Measurements and Modeling. Radioengineering, vol. 23, no. 3, September 2014.

13. Yang S.,C., OFDMA System Analysis And Design, Artech House 2010

14. Marczak A., Performance analysis of data transmission in MC-CDMA radio interface with turbo code. Telecommunication Systems, DOI 10.1007/s11235-0149910-7, December 2014.

15. Gajewski S., Throughput - Coverage Characteristics for Soft and Partial Frequency Reuse in the LTE Downlink. In proc. of 36th International conf. on telecommunications and signal processing, TSP 2013, pp. 199-203, Rome , Italy 2013.

16. Hindias M. N., Khanam S., Reza A. W., Ghaleb A. M., Latef A. L., Frequency Reuse for 4G Technologies: A Survey. In proc. of The 2nd International Conference on Mathematical Sciences \& Computer Engineering (ICMSCE 2015), At Langkawi, Malaysia, 2015.

\section{CONTACT WITH THE AUTHOR}

Sławomir Gajewski

The Faculty of Electronics, Telecommunications and Informatics Gdansk University of Technology 11/12 Narutowicza St. 80-233 Gdańsk Poland 